\title{
Prevalence of Anti-SARS-CoV-2 Antibody in Hospital Staff in Double-Center Setting: A Preliminary Report of a Cohort Study From
}

\section{Iran}

\author{
Kamran Bagheri Lankarani (iD ${ }^{1}$, Behnam Honarvar (iD ${ }^{1}$, Navid Omidifar (iD ${ }^{2,3}{ }^{,}$, Majid Pakdin (iD) ${ }^{1}$, \\ Mohsen Moghadami (iD ${ }^{4}$, Mansoureh Shokripour ${ }^{2}$, Seyed Abolfazl Dorraninejad (iD ${ }^{4}$, Kazem Samadi ${ }^{5}$, \\ Mostafa Chashmpoosh ${ }^{2}$, Fatemeh Pourataei ${ }^{2}$, Mastooreh Boostani ${ }^{2}$, Mir Behrad Aghazadeh ${ }^{6}$, \\ Hengameh Dehghan ${ }^{7}$ and Fatemeh Rafiei ${ }^{1}$
}

\author{
Health Policy Research Center, Institute of Health, Shiraz University of Medical Sciences, Shiraz, Iran \\ ${ }^{2}$ Department of Pathology, Shiraz University of Medical Sciences, Shiraz, Iran \\ ${ }^{3}$ Clinical Education Research Center, Shiraz University of Medical Sciences, Shiraz, Iran \\ ${ }^{4}$ Department of Internal Medicine, Shiraz University of Medical Sciences, Shiraz, Iran \\ ${ }^{5}$ Department of Anesthesiology, Shiraz University of Medical Sciences, Shiraz, Iran \\ ${ }^{6}$ Department of Biochemistry, Shiraz University of Medical Sciences, Shiraz, Iran \\ ${ }^{7}$ Department of Cell Biology, Islamic Azad University, Kazerun, Iran \\ "Corresponding author: Department of Pathology, Shiraz University of Medical Sciences, Shiraz, Iran; Clinical Education Research Center, Shiraz University of Medical Sciences, \\ Shiraz, Iran. Email: omidifar@gmail.com
}

Received 2021 January 03; Accepted 2021 January 08.

\begin{abstract}
Background: The outbreak of COVID-19 in China in late 2019 was an unprecedented catastrophe that also involved many other countries, including Iran. Concerning the danger of disease contagion, it is necessary to detect asymptomatic or mild cases, especially in hospital staff who are highly exposed to the disease.

Objectives: In this serosurvey study, we aimed to estimate IgG seroprevalence among hospital staff in two public hospitals to determine local transmission and infection risk factors, as well as protective immunity among high-risk populations.

Methods: Screening was offered to the hospital staff of two public hospitals in Shiraz, Iran. Screening involved the measurement of IgG antibodies against SARS-CoV-2. Besides, a checklist that consisted of questions about sociodemographic, occupational, and epidemiological characteristics was completed by the participants.

Results: Among 494 participants in this study, 29 (5.8\%) had anti-SARS-CoV-2 IgG in their blood. Besides, 320 (64.8\%) had at least one of the clinical symptoms within six months before this survey. Among participants with positive PCR, nine (21.4\%) had anti-SARS-CoV2 IgG, while this figure was seven (33.3\%) for individuals with positive CT scans. Non-proper disposal of used protective equipment or infectious wastes $(\mathrm{OR}=26.5)$, rotational daily work shifts $(\mathrm{OR}=7.5)$, being anxious about getting COVID-19 $(\mathrm{OR}=3.8)$, and age $(\mathrm{OR}$ $=1.06$ ) were the significant determinants of having anti-SARS-CoV-2 IgG in the hospital staff.

Conclusions: It is essential to continue training and giving technical consultations about COVID-19, especially the proper disposal of used protective equipment or infectious wastes in rotational daily shift workers.
\end{abstract}

Keywords: COVID-19, SARS-CoV-2, Healthcare Workers, Hospital Staff, Surveillance, Infection Control

\section{Background}

In late 2019, East Asia confronted an unexpected fatal respiratory disease that affected thousands of population. This type of severe acute respiratory syndrome(SARS), which was named SARS coronavirus 2 (SARS-CoV-2) or coronavirus disease 2 (COVID-19), spread rapidly and involved many countries with exponential growth (1). Iran was among the first countries involved in this pandemic, so that from the first officially reported case on 20 February
2020 (1) until 28 October 2020, 738,322 confirmed cases of COVID-19 and 40,582 deaths were reported across the coun$\operatorname{try}(2)$.

As known, COVID-19 has a wide range of severity from asymptomatic or mild to severe and rapidly fatal (3-6), while a significant number of these cases remain undetected, which is a challenging epidemiological issue (7). Therefore, detecting mild cases or asymptomatic carriers is important for implementing effective preventive mea- 
sures in high-risk settings such as hospitals (8). To this aim, serological assays, which can define immunity based on seroprevalence, play a key role in detecting asymptomatic or previously exposed ones (8-10). Indeed, serosurvey has two major benefits; first, it can be used as a tool to determine local transmission and infection risk factors $(9,10)$, and second, it can be used to estimate protective immunity (9).

Healthcare workers (HCWs) are deemed to be at high risk due to their profession as frontline fighters against the disease $(8,11)$. Among HCWs, hospital staff (HS) are specifically at a high risk of infection. It is estimated that about 7,000 HCWs died worldwide until early September 2020 (12), and about 300 HCWs lost their lives in Iran up to early October 2020 due to COVID-19 (13). Besides, multiple factors can predispose HCWs to different psychological disorders during this pandemic (14), and monitoring their serological immunity status may help manage their psychological status regarding contracting this disease. On the other hand, HS burnout during this pandemic should not be overlooked, especially in the next months, when we may face a co-epidemic of COVID-19 and influenza, which increases the workload of hospitals more than before (15, 16). Therefore, it is necessary to define and monitor seroimmunity and risk factors of coronavirus infection in HS to protect them against this disease, which guides policymakers to make proper decisions to control the disease spread in hospitals (8).

It is revealed that in many patients with COVID-19, IgG can be detected before IgM appearance or at the same time (17). It is a good indicator of long-term immunity after contact with the virus (18). A study showed that anti-SARS-CoV2 (IgG) presence is $40 \%$ in COVID-19 cases after less than a week of their symptoms' onset, while this value increases up to $79.8 \%$ by day 15 after the onset of symptoms (19). Therefore, it is a reliable value to detect seroprevalence in cases presenting $>14$ days after the onset of symptoms with a sensitivity and specificity of $96.2 \%$ and $96.6 \%$, respectively (20).

\section{Objectives}

We aimed to assess the seroprevalence of COVID-19 IgG in HS.

\section{Methods}

\subsection{Study Design, Participants, and Data Collection}

A cross-sectional serosurvey was conducted from July 13 to August 5, 2020, among HS including medical, paramedical, and administrative staff from two main hospitals of Shiraz City, with two million population as the capital city of Fars Province in the south of Iran. Finally, 494 HCWs were conveniently recruited based on their willingness to take part in the study. First, trained interviewers were asked to complete a checklist that consisted of questions about socio-demographic, occupational, and epidemiological characteristics. Having an underlying medical condition, prior COVID-19 infection or symptoms, conducting real-time polymerase chain reaction (RT-PCR), or lung computed tomography (CT) were also queried. We asked about risk perception, observance of isolation precaution (standard, droplet, airborne, contact), and passing its related course. The filling of checklists was individually done faceto-face in private. One of the selected hospitals was AliAsghar Hospital, which was the main referral center for COVID-19 cases. Another hospital was Dastgheib Hospital, which was a general hospital. The reason for choosing the second hospital was to reveal any probable difference in the measured items between the two hospitals, one of which was dedicated to COVID-19 cases while the other was not.

\subsection{Serologic Measurement}

About $5 \mathrm{~mL}$ of blood was taken from each participant. After centrifugation, the isolated sera were kept at $-80^{\circ} \mathrm{C}$ until testing. The IgG level was measured according to the World Health Organization (WHO) guidelines (21) using an anti-SARS-CoV-2 ELISA kit (Pishtaz Co. ${ }^{\circledR}$ ). In summary, 96well plates were coated (100 ng/well) overnight with recombinant nucleoprotein (22), and then incubated with diluted serum samples at 1:101. The optical density (OD) (450 nm-630 nm) was measured. The cutoff value was calculated as the mean of negative serum OD plus 0.15 . Then, the OD of the sample was divided by the calculated cutoff value to determine the cutoff index. The cutoff indices above 1.1 were considered as positive tests, and the cutoff indices below 0.9 were considered as negative tests $(19,23)$. For indices in the gray zone (0.9-1.1), testing was repeated by retaking the blood sample (maximum of three times) to achieve a definite value. Also, quality assurance was done by rechecking the data in another laboratory. A positive test indicated that the anti-SARS-CoV-2 (IgG) antibody was present in the blood.

\subsection{Statistical Analysis}

All statistical analyses were performed using SPSS 20.0. Mean, and the standard deviation was used to present continuous variables, while categorical variables were shown as frequency and percentage. Univariate analysis was done using parametric tests (t-test) and nonparametric tests (chi-squared). Multivariable analysis was also done after 
checking collinearity and VIF factors using logistic regression (enter method), considering P values $<0.05$ as the significance level.

\subsection{Ethical Approval and Consent to Participate}

All subjects gave their written informed consent, while voluntary participation in all stages of this study was respected. Privacy was assured in all steps of the study, including interviews, data gathering, recording, analysis, and reporting. The results of antibody titers were sent for each of the participants by the Short Message service (SMS) based on their requests. The protocol of this study followed the ethical guidelines of the 1975 Declaration of Helsinki as approved by the Shiraz University of Medical Sciences (SUMS) Ethics Committee with registration number IR.SUMS.REC.1399.314.

\section{Results}

Among 494 participants in this study, 282 (57\%) were from Ali-Asghar Hospital (COVID-19 referral hospital) and 212 (43\%) from Dastgheib Hospital (general hospital). In general, 29 (5.9\%) participants had anti-SARS-CoV-2 IgG antibodies, including 18 (6.4\%) from the first hospital and 11 (5.2\%) from the second hospital $(P=0.3)$. The mean age of the participants was $37.4 \pm 8.8$ years (min-max: $21-76$ ), and the female (311) to male (183) ratio was 1.7. Of all the subjects, 355 (71.9\%) were married compared to 139 (28.1\%) who were single. Besides, 397 (80.4\%) subjects were university graduates. Furthermore, 29 (5.9\%) were medical doctors, and 155 (31.4\%) were nurses, while 310 (62.8\%) had been working in other fields such as operation rooms (7.9\%), laboratories (5.9\%), management (4.3\%), health sciences (4.3\%), and other paramedics (40.5\%). Of 494 participants, 180 (36.4\%) had official and 306 (61.9\%) had non-official (contractual, mandatory) employment status. The duration of employment was $7.8 \pm 7.3$ years (min-max: 1 - 31), and their positions in the hospital were as follows: 142 (28.7\%) is highly critical wards, 159 (32.2\%) in semi-critical wards, and 193 (39.1\%) in low critical departments of the hospital. We defined the following wards as highly critical departments: Emergency, triage, ICU, isolation room, operation room, and recovery room. Semi-critical parts consisted of admission wards, reception, out-patient clinics, laboratory, pharmacy, radiology, EKG unit, and rehabilitation department. Low critical sections were management, security, transport section, laundry, kitchen, morgue, engineering, research centers, and repository.

Among the staff, 318 (64.4\%) had rotational and 164 (32.2\%) had fixed work shifts. Out of all HCWs, 132 (26.7\%) reported a kind of chronic disease such as gastrointestinal, psychological, pulmonary, hypertension, cardiac, diabetes mellitus, rheumatologic, and allergy. Among 494 subjects, 403 (81.6\%) stated that they had a full-time job in the hospital, 221(44.7\%) had had close contact with COVID19-confirmed patients, 123 (24.9\%) had a history of traveling to other cities or provinces at least once, and 79 (16\%) were the host of traveler(s) from other cities or provinces in the period between the beginning of COVID-19 epidemic and the time of this study. Moreover, 320 (64.8\%) had at least one of the clinical symptoms within six months before this survey, including headache (28.3\%), myalgia (24.1\%), sore throat (23.7\%), dry cough (16.2\%), arthralgia (15\%), fever (15.4\%), rhinorrhea (14.2\%), chest discomfort (13.6\%), sneezing (12.8\%), dyspnea (12.1\%), diarrhea (10.3\%), chills (10.9\%), productive cough (8.5\%), nausea (7.1\%), anosmia (2.4\%), vomiting (2\%), and ageusia (1.4\%). Among all of studied HS, 347 (70.2\%) had been sampled from their nasopharynx and oropharynx and tested by polymerase chain reaction (PCR) for COVID-19, while 42 (12.1\%) were positive, and out of 103 (20.8\%) for whom CT scan of the lungs had been done before, 21 (20.4\%) were positive for COVID19 , based on self-reports (Table 1). Furthermore, among individuals with positive PCR, nine (21.4\%) had anti-SARSCoV-2 IgG, while this figure was seven (33.3\%) for individuals with positive CT scans (Table 2). Among all responders, 213 (43.1\%) were highly concerned and anxious about becoming infected with COVID-19 in the hospital, while 341 (69\%) reported that their families had a high level of anxiety about this issue. Among interviewees, 223 (45.1\%) considered COVID-19 as a severe and virulent disease. Table 1 shows the comparison of demographic, epidemiological, clinical, paraclinical, and risk perception characteristics in both studied hospitals.

Table 3 shows the difference between isolation precautions, which were observed in the two studied hospitals. As a standard precaution, regular and proper handwashing before and after contact with any patient and before and after using gloves was observed by 326 (66\%) and 311 (63\%) of the hospital staff, respectively. Wearing gloves before contact with patients or their specimens was observed by 285 (57.7\%), while proper disposal of used protective equipment or infectious waste and disinfection of surfaces and equipment that were in close contact with patients all or most of the time were applied by 310 (62.8\%) and 295 (59.7\%) of the interviewees, respectively. As the droplet precaution, keeping a distance of at least 1.5 meters from patients suspected of COVID-19 and wearing a medical or surgical mask while being in close contact with them were observed by 292 (59.1\%) and 314 (63.6\%) of the respondents, respectively. Considering contact precautions, goggles or face shields were used by 231 (46.8\%), and wearing a surgical gown was 
reported by 233 (47.2\%) in the case of being in close contact with a patient suspected of COVID-19. As the airborne precaution, putting on filtered masks if the patient's respiratory particles were suspected to be aerosolized (e.g., in bronchoscopy, endoscopy, respiratory and cardiovascular resuscitation), was applied by $227(46 \%)$. Out of all respondents, $357(72.3 \%$ ) had passed education about isolation precautions regarding COVID-19.

The univariable analysis showed that hospital health workers whose daily work shifts were rotational (7.9\%) were more likely to have anti-SARS-CoV-2 IgG than the ones with fixed shifts $(1.8 \%)(P=0.007)$ (Table 2). Moreover, having $\operatorname{IgG}$ was more prevalent in individuals who had not accurately followed the proper disposal of used protective equipment or infectious wastes (42.9\%) than in the counterpart group $(5.2 \%)(\mathrm{FE}=0.006)$ (Table 2).

Multivariable analysis revealed that non-proper disposal of used protective equipment or infectious wastes $(\mathrm{OR}=26.5)$, rotational daily work shifts $(\mathrm{OR}=7.5)$, being anxious about getting infected with COVID-19 (OR $=3.8$ ), and age $(\mathrm{OR}=1.06)$ were the significant determinants of having anti-SARS-CoV-2 IgG in HS (Table 4).

\section{Discussion}

This study showed that about one out of $17 \mathrm{HS}$ had antiSARS-CoV-2 IgG, and no significant difference was noticed in the seroprevalence of COVID-19 IgG between the main referral and general hospitals. However, older HS, those who were more anxious, those who had rotational daily work shifts, and especially those that implemented improper disposal of used protective equipment or infectious wastes had a higher probability of the previous infection with this virus.

Studies about the seroprevalence of COVID-19 IgG in different clinical settings have various findings. Seroprevalence varies from $0.74 \%$ among medical staff in a retrospective study, which was performed at a hospital in Fujisawa, Japan (24), to 17\% among high-risk healthcare workers on day 14 in an observational study conducted in Nanjing Drum Tower Hospital in China (8). Other surveys showed the IgG seroprevalence among HCWs was 11\% (Brussel, Belgium) (11), 1.2\% (Essen, Germany) (25), 0.83\% ( New Jersey, USA) (20), 2.0\% (Wuhan, China) (26), 1.7\% (Naples, Italy)(27), 1.6\% (Indianapolis, USA) (28), 2.7\% (Copenhagen, Denmark) (29), 7.4\% (Milan, Italy) (30), and 4.9\% (Michigan, USA) (31). These findings are more or less similar to our findings. The different results may be due to various methodologies. For instance, Brussel et al.'s study was performed two weeks after the first epidemiological wave with Ig seroprevalence estimation of 11\% at baseline (11), while Essen et al.'s study was performed about two weeks before this wave with IgG seroprevalence estimation of 1.2\% (25). Part of data collection coincided with the second epidemiological wave of the disease in Iran, which could have raised the seroprevalence rate.

Also, it was revealed that non-proper disposal of used protective equipment or infectious wastes was the most significant determinant of having anti-SARS-CoV-2 IgG in HS. Indeed, proper disposal of used protective equipment differs from the proper use of protective equipment, which should not be overlooked by the nosocomial infection control team, especially as about one-third of HS had not passed education and training about COVID-19 isolation precautions. Another study that highlighted the importance of assessing the seroprevalence of COVID-19 immunity among HS emphasized the proper protection awareness of HCWs (26).

We also found that HCWs with rotational shifts were more susceptible to becoming infected with COVID-19 than HCWs with fixed shifts. It may be due to the different COVID-19 exposure rates among morning, afternoon, and evening shift workers and the possible adverse effect of rotational work shifts on human immunity, as a recent study showed that night shift, working can influence the immune system (32).

Furthermore, we found that being anxious about getting the disease (which was seen in about half of the HS) increased the chance of becoming infected. Anxiety is also one of the factors that can impact the immune system (33), and it can be the result of some misunderstanding about COVID-19 among HCWs that leads to obsession. Therefore, it is essential to decrease anxiety (1) in HS via continuous mental support and training for them.

We also realized that being older is a determinant that can slightly increase the positivity of anti-SARS-CoV-2 IgG. However, another study did not show such a significant difference (26).

This survey also revealed that no significant difference existed in the rates of seropositivity of anti-COVID-19 IgG between HS with different positions in the hospital (highly critical, semi-critical, and low critical departments). This may suggest that the hospitals are well protected in all parts and that a high rate of exposure to SARS-CoV-2 occurred outside the hospital. Another study came to the same conclusion according to the evaluated risk factors (31).

\subsection{Strengths and Limitations}

As a strong point, this study was performed in a doublecenter setting (a COVID-19 main referral hospital and a general hospital), which provided making a comparison between them, considering different clinical, paraclinical, socioeconomic, and infection control variables. However, 


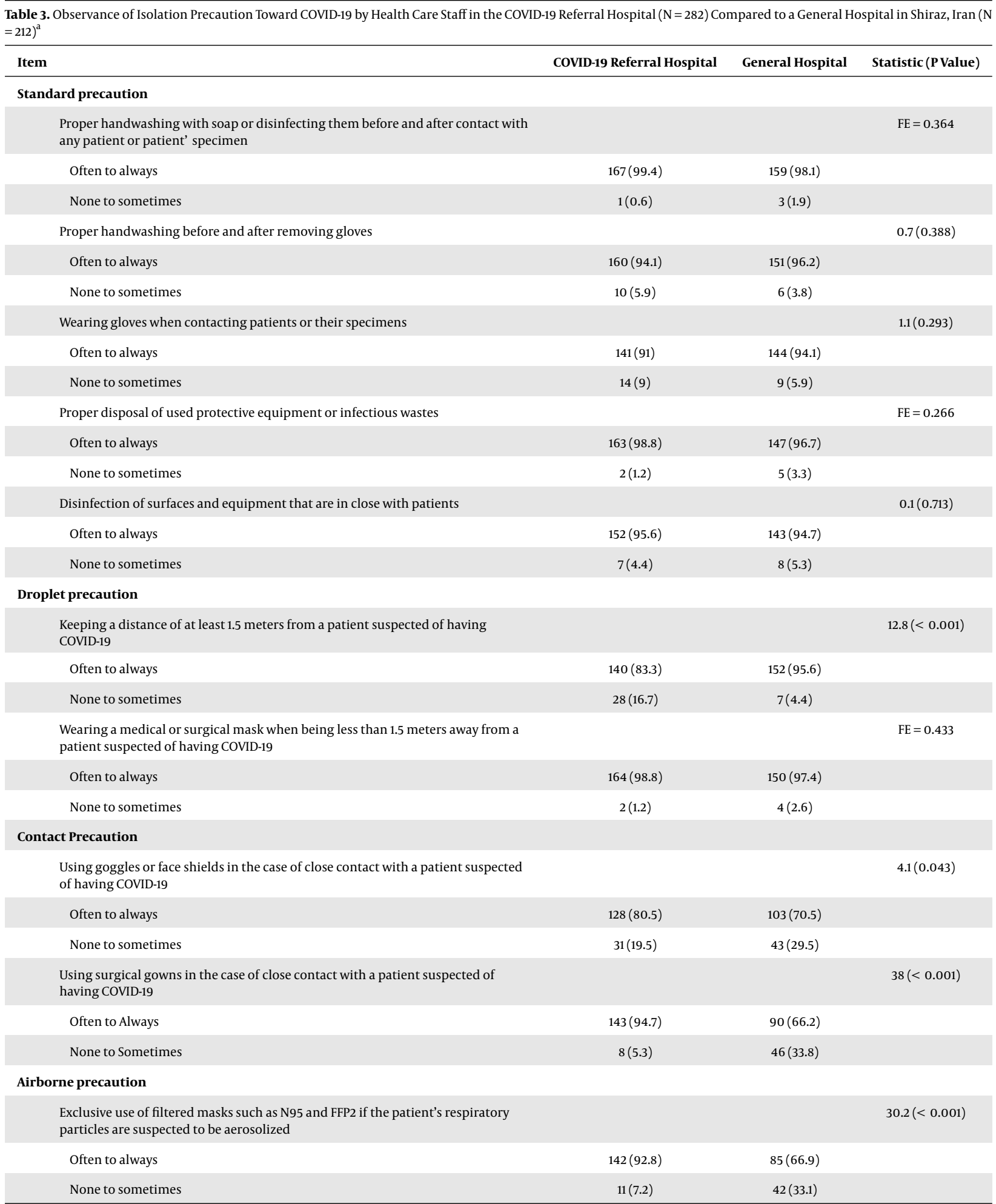

${ }^{\mathrm{a}}$ Values are expressed as No. (\%). 


\begin{tabular}{|c|c|c|c|c|}
\hline Variable & B & EXP B & 95\% CI & P-Value \\
\hline Constant & -7.47 & 0.001 & - & $<0.001$ \\
\hline Age & 0.059 & 1.06 & $1.01-1.11$ & 0.018 \\
\hline Being anxious about getting COVID-19 & 1.33 & 3.8 & $1.3-10.9$ & 0.013 \\
\hline Rotational versus fixed work shifts in the hospital & 2.02 & 7.5 & $1.4-40.4$ & 0.018 \\
\hline Non-proper disposal of used protective equipment or infectious wastes & 3.2 & 26.5 & $2.9-236.3$ & 0.003 \\
\hline
\end{tabular}

this study had some limitations. We could not conduct a longitudinal serosurvey (due to the logistic and budget shortages); however, the findings can be used as a baseline for future serosurveys. Moreover, the sampling method was convenient, although the participants were from nearly all sections of the hospitals.

\subsection{Conclusion}

The majority of HS did not have anti-SARS-CoV-2 IgG even though they had anxiety about getting this disease. Continuous training and providing technical consultation about this disease, especially the proper disposal of used protective equipment or infectious wastes in rotational daily shift workers, is recommended, while psychological support of HS should not be neglected.

\section{Acknowledgments}

Conducting this study is due to the cooperation of hospital staff who accepted to be the participants of the study. We sincerely thank them all.

\section{Footnotes}

Authors' Contribution: All listed authors meet the International Committee of Medical Journal Editors (ICMJE) criteria. We attest that all authors contributed significantly to the creation of this manuscript, each having fulfilled criteria as established by the ICMJE. All named authors have seen and agreed with the submitted version of the paper. All who are included in the acknowledgment section, or are providers of personal communications, have agreed with those inclusions, and confirm that the material is original, unpublished, and has not been submitted elsewhere.

Conflict of Interests: The authors declare that they have no conflict of interest.

Ethical Approval: The protocol of this study followed the ethical guidelines of the 1975 Declaration of Helsinki as approved by the Shiraz University of Medical Sciences (SUMS) Ethics Committee with registration number
IR.SUMS.REC.1399.314. All listed authors meet the International Committee of Medical Journal Editors (ICMJE) criteria.

Funding/Support: This study was funded by the Shiraz University of Medical Sciences.

Informed Consent: Privacy was assured in all steps of the study, including interviews, data gathering, recording, analysis, and reporting. The results of antibody titers were sent for each of the participants by the Short Message service (SMS) based on their requests. All subjects provided written informed consent, while voluntary participation in all stages of this study was respected.

\section{References}

1. Honarvar B, Lankarani KB, Kharmandar A, Shaygani F, Zahedroozgar M, Rahmanian Haghighi MR, et al. Knowledge, attitudes, risk perceptions, and practices of adults toward COVID-19: A population and field-based study from Iran. Int J Public Health. 2020;65(6):731-9. doi: 10.1007/s00038-020-01406-2. [PubMed: 32583009]. [PubMed Central: PMC7311321].

2. Worldometer. World/countries /Iran. Worldometer; 2020, [updated 14 Feb 2021; cited 13 Nov]. Available from: https://www.worldometers. info/coronavirus/country/iran/.

3. Xu XW, Wu XX, Jiang XG, Xu KJ, Ying LJ, Ma CL, et al. Clinical findings in a group of patients infected with the 2019 novel coronavirus (SARS-Cov-2) outside of Wuhan, China: Retrospective case series. BMJ. 2020;368:m606. doi: 10.1136/bmj.m606. [PubMed: 32075786]. [PubMed Central: PMC7224340].

4. Wang D, Hu B, Hu C, Zhu F, Liu X, Zhang J, et al. Clinical characteristics of 138 hospitalized patients with 2019 novel coronavirusinfected pneumonia in Wuhan, China. JAMA. 2020;323(11):1061-9. doi: 10.1001/jama.2020.1585. [PubMed: 32031570]. [PubMed Central: PMC7042881].

5. Lin M, Wei L, Xie L, Zhu G, Dela Cruz CS; Chang, et al. Epidemiologic and clinical characteristics of novel coronavirus infections involving 13 patients outside Wuhan, China. JAMA. 2020;323(11):1092-3. doi: 10.1001/jama.2020.1623. [PubMed: 32031568]. [PubMed Central: PMC7042871].

6. Huang R, Xia J, Chen Y, Shan C, Wu C. A family cluster of SARSCoV-2 infection involving 11 patients in Nanjing, China. Lancet Infect Dis. 2020;20(5):534-5. doi: 10.1016/S1473-3099(20)30147-X. [PubMed: 32119823]. [PubMed Central: PMC7159019].

7. Pan A, Liu L, Wang C, Guo H, Hao X, Wang Q, et al. Association of public health interventions with the epidemiology of the COVID-19 outbreak in Wuhan, China. JAMA. 2020;323(19):1915-23. doi: 10.1001/jama.2020.6130. [PubMed: 32275295]. [PubMed Central: PMC7149375]. 
8. Chen Y, Tong X, Wang J, Huang W, Yin S, Huang R, et al. High SARS-CoV2 antibody prevalence among healthcare workers exposed to COVID19 patients. J Infect. 2020;81(3):420-6. doi: 10.1016/j.jinf.2020.05.067. [PubMed: 32504745]. [PubMed Central: PMC7270786].

9. Fafi-Kremer S, Bruel T, Madec Y, Grant R, Tondeur L, Grzelak L, et al. Serologic responses to SARS-CoV-2 infection among hospital staff with mild disease in eastern France. EBioMedicine. 2020;59:102915. doi: 10.1016/j.ebiom.2020.102915. [PubMed: 32747185]. [PubMed Central: PMC7502660].

10. Biggs HM, Harris JB, Breakwell L, Dahlgren FS, Abedi GR, Szablewski $\mathrm{CM}$, et al. Estimated community seroprevalence of SARS-CoV-2 antibodies - Two Georgia counties, April 28-May 3, 2020. MMWR Morb Mortal Wkly Rep.2020;69(29):965-70. doi:10.15585/mmwr.mm6929e2. [PubMed: 32701941]. [PubMed Central: PMC7377817].

11. Martin C, Montesinos I, Dauby N, Gilles C, Dahma H, Van Den Wijngaert S, et al. Dynamics of SARS-CoV-2 RT-PCR positivity and seroprevalence among high-risk healthcare workers and hospital staff. J Hosp Infect. 2020;106(1):102-6. doi: 10.1016/j.jhin.2020.06.028. [PubMed: 32593608]. [PubMed Central: PMC7316468].

12. Niall McCarthy. Amnesty analysis reveals over 7,000 health workers have died from COVID-19. London, United Kingdom: Amnesty International; 2020, [cited 3 Sep]. Available from: https://www.amnesty.org/en/latest/news/2020/09/amnestyanalysis-7000-health-workers-have-died-from-covid19/.

13. Young Journalists Club. The death of 300 health defenders. Tehran, Iran: Young Journalists Club; 2020, [cited 2 Oct]. Available from: https:// www.yjc.ir/00VW96.

14. Robert R, Kentish-Barnes N, Boyer A, Laurent A, Azoulay E, Reignier J. Ethical dilemmas due to the Covid-19 pandemic. Ann Intensive Care. 2020;10(1):84. doi: 10.1186/s13613-020-00702-7. [PubMed: 32556826]. [PubMed Central: PMC7298921].

15. Miller IF, Becker AD, Grenfell BT, Metcalf CJE. Disease and healthcare burden of COVID-19 in the United States. Nat Med. 2020;26(8):1212-7. doi: 10.1038/s41591-020-0952-y. [PubMed: 32546823].

16. Grech V, Borg M. Influenza vaccination in the COVID-19 era. Early Hum Dev. 2020;148:105116. doi: 10.1016/j.earlhumdev.2020.105116. [PubMed: 32604011]. [PubMed Central: PMC7301816].

17. Xiang F, Wang X, He X, Peng Z, Yang B, Zhang J, et al. Antibody detection and dynamic characteristics in patients with coronavirus disease 2019. Clin Infect Dis. 2020;71(8):1930-4. doi: 10.1093/cid/ciaa461. [PubMed: 32306047]. [PubMed Central: PMC7188146]

18. Brandstetter S, Roth S, Harner S, Buntrock-Dopke H, Toncheva AA, Borchers N, et al. Symptoms and immunoglobulin development in hospital staff exposed to a SARS-CoV-2 outbreak. Pediatr Allergy Immunol. 2020;31(7):841-7. doi:10.1111/pai.13278. [PubMed:32413201].

19. Okba NM, Müller MA, Li W, Wang C, GeurtsvanKessel CH, Corman VM, et al. SARS-CoV-2 specific antibody responses in COVID-19 patients. medRxiv. 2020. doi:10.1101/2020.03.18.20038059.

20. Mughal MS, Kaur IP, Patton CD, Mikhail NH, Vareechon C, Granet KM The prevalence of severe acute respiratory coronavirus virus 2 (SARS CoV-2) IgG antibodies in intensive care unit (ICU) healthcare personnel (HCP) and its implications-a single-center, prospective, pilot study. Infect Control Hosp Epidemiol. 2020:1-2. doi: 10.1017/ice.2020.298. [PubMed: 32530392]. [PubMed Central: PMC7322146].

21. World Health Organization. Laboratory testing for coronavirus disease (COVID-19) in suspected human cases. Geneva, Switzerland: WHO;2020 [updated 19 Mar 2020; cited 17 Jan]. Available from: https://www.who. int/publications/i/item/10665-331501.
22. Zhang W, Du RH, Li B, Zheng XS, Yang XL, Hu B, et al. Molecular and serological investigation of 2019-nCoV infected patients: implication of multiple shedding routes. Emerg Microbes Infect. 2020;9(1):3869. doi: 10.1080/22221751.2020.1729071. [PubMed: 32065057]. [PubMed Central: PMC7048229].

23. Li M, Jin R, Peng Y, Wang C, Ren W, Lv F, et al. Generation of antibodies against COVID-19 virus for development of diagnostic tools. medRxiv. 2020. doi: 10.1101/2020.02.20.20025999.

24. Hibino M, Iwabuchi S, Munakata H. SARS-CoV-2 IgG seroprevalence among medical staff in a general hospital that treated patients with COVID-19 in Japan: Retrospective evaluation of nosocomial infection control. J Hosp Infect. 2021;107:103-4. doi: 10.1016/j.jhin.2020.10.001. [PubMed: 33039454]. [PubMed Central: PMC7544697].

25. Korth J, Wilde B, Dolff S, Anastasiou OE, Krawczyk A, Jahn M, et al. SARSCoV-2-specific antibody detection in healthcare workers in Germany with direct contact to COVID-19 patients. J Clin Virol. 2020;128:104437. doi: 10.1016/j.jcv.2020.104437. [PubMed: 32434708]. [PubMed Central: PMC7219425]

26. Zhou F, Li J, Lu M, Ma L, Pan Y, Liu X, et al. Tracing asymptomatic SARS CoV-2 carriers among 3674 hospital staff: A cross-sectional survey. EClinicalMedicine. 2020;26:100510. doi: 10.1016/j.eclinm.2020.100510. [PubMed: 32954232]. [PubMed Central: PMC7490283].

27. Fusco FM, Pisaturo M, Iodice V, Bellopede R, Tambaro O, Parrella $\mathrm{G}$, et al. COVID-19 among healthcare workers in a specialist infectious diseases setting in Naples, Southern Italy: Results of a cross-sectional surveillance study. J Hosp Infect. 2020;105(4):596-600. doi: 10.1016/j.jhin.2020.06.021. [PubMed: 32565367]. [PubMed Central: PMC7301109].

28. Hunter BR, Dbeibo L, Weaver CS, Beeler C, Saysana M, Zimmerman MK, et al. Seroprevalence of severe acute respiratory coronavirus virus 2 (SARS-CoV-2) antibodies among healthcare workers with differing levels of coronavirus disease 2019 (COVID-19) patient exposure. Infect Control Hosp Epidemiol. 2020;41(12):1441-2. doi: 10.1017/ice.2020.390. [PubMed: 32741406]. [PubMed Central: PMC7445457].

29. Iversen $\mathrm{K}$, Bundgaard $\mathrm{H}$, Hasselbalch RB, Kristensen JH, Nielsen $\mathrm{PB}$, Pries-Heje M, et al. Risk of COVID-19 in health-care workers in Denmark: An observational cohort study. Lancet Infect Dis. 2020;20(12):1401-8. doi: 10.1016/S1473-3099(20)30589-2. [PubMed: 32758438]. [PubMed Central: PMC7398038].

30. Sotgiu G, Barassi A, Miozzo M, Saderi L, Piana A, Orfeo N, et al. SARSCoV-2 specific serological pattern in healthcare workers of an Italian COVID-19 forefront hospital. BMC Pulm Med. 2020;20(1):203. doi: 10.1186/s12890-020-01237-0. [PubMed: 32727446]. [PubMed Central: PMC7388425].

31. Dimcheff DE, Schildhouse RJ, Hausman MS, Vincent BM, Markovitz E, Chensue SW, et al. Seroprevalence of severe acute respiratory syndrome coronavirus-2 (SARS-CoV-2) infection among Veterans Affairs healthcare system employees suggests higher risk of infection when exposed to SARS-CoV-2 outside the work environment. Infect Control Hosp Epidemiol. 2020:1-7. doi: 10.1017/ice.2020.1220. [PubMed: 32962771]. [PubMed Central: PMC7578654].

32. Loef B, Nanlohy NM, Jacobi RHJ, van de Ven C, Mariman R, van der Beek AJ, et al. Immunological effects of shift work in healthcare workers. Sci Rep. 2019;9(1):18220. doi: 10.1038/s41598-019-54816-5. [PubMed: 31796836]. [PubMed Central: PMC6890754].

33. Ray A, Gulati K, Rai N. Stress, anxiety, and immunomodulation: A pharmacological analysis. Vitam Horm. 2017;103:1-25. doi: 10.1016/bs.vh.2016.09.007. [PubMed: 28061967]. 
Table 1. General, Epidemiological, Clinical, Paraclinical, and Risk Perception Characteristics of Health Care Staff in the COVID-19 Referral Hospital Compared to a General Hospital in Shiraz, Iran $(\mathrm{N}=494)^{\mathrm{a}}$

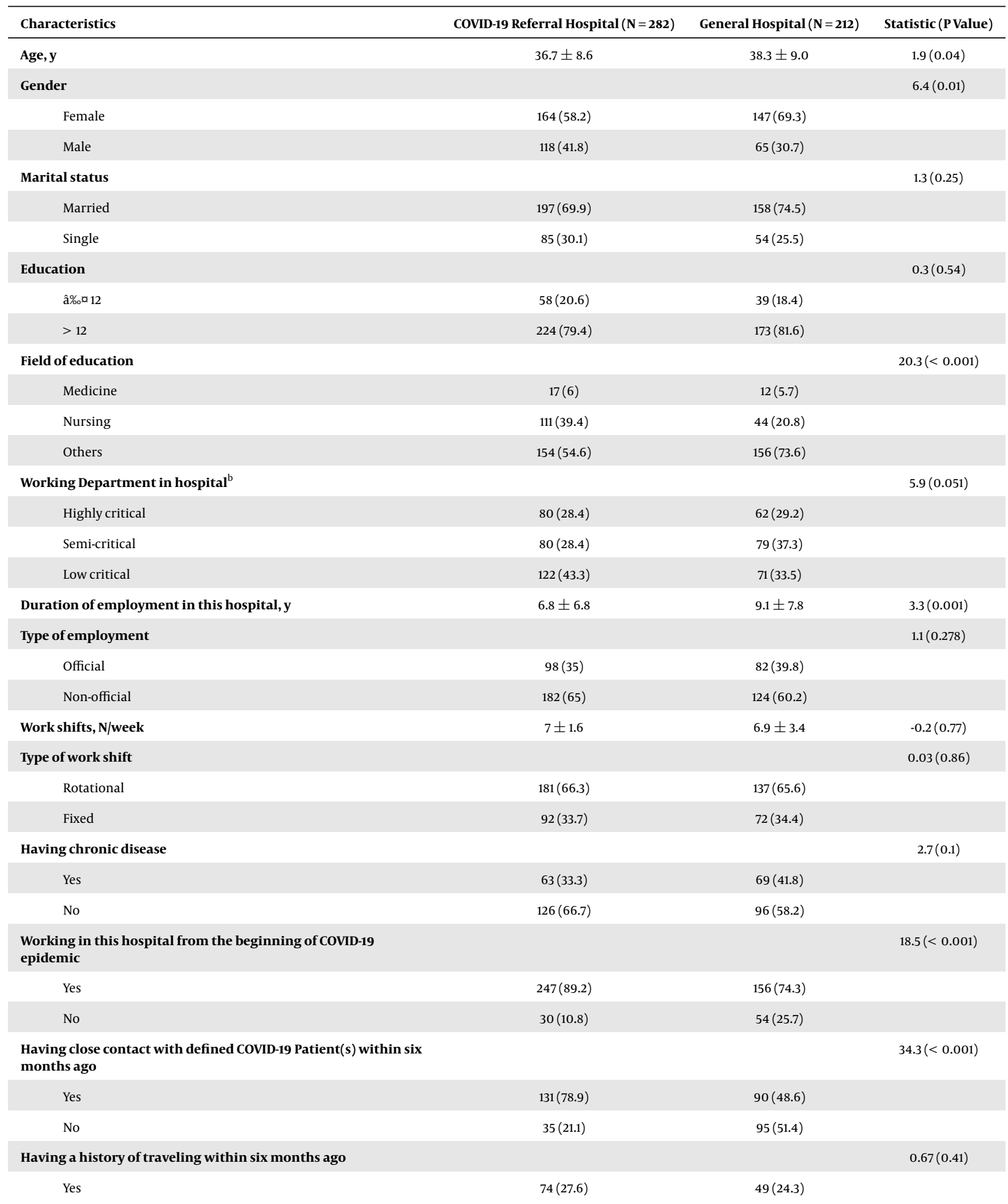




\begin{tabular}{|c|c|c|c|}
\hline No & $194(72.4)$ & $153(75.7)$ & \\
\hline Being the host of traveler(s) within six months ago & & & $4.4(0.036)$ \\
\hline Yes & $36(13.6)$ & $43(20.9)$ & \\
\hline No & $229(86.4)$ & $163(79.1)$ & \\
\hline Having COVID-19 symptom(s) within six months ago & & & $7.1(0.007)$ \\
\hline Yes & $195(71.4)$ & $125(59.8)$ & \\
\hline No & $78(28.6)$ & $84(40.2)$ & \\
\hline \multicolumn{4}{|l|}{ Type of symptoms within six months ago } \\
\hline Fever & & & $0.2(0.604)$ \\
\hline Yes & $48(24.4)$ & $28(21.9)$ & \\
\hline No & $149(75.6)$ & $100(78.1)$ & \\
\hline Cough & & & $0.001(0.981)$ \\
\hline Yes & $69(35)$ & $45(35.2)$ & \\
\hline No & $128(65)$ & $83(64.8)$ & \\
\hline Dyspnea & & & $4.9(0.026)$ \\
\hline Yes & $44(22.3)$ & $16(12.5)$ & \\
\hline No & $153(77.7)$ & $112(87.5)$ & \\
\hline Chest discomfort & & & $4.2(0.038)$ \\
\hline Yes & $48(24.4)$ & $19(14.8)$ & \\
\hline No & $149(75.6)$ & $109(85.2)$ & \\
\hline Myalgia & & & $4.3(0.037)$ \\
\hline Yes & $81(41.1)$ & $38(29.7)$ & \\
\hline No & $116(58.9)$ & $90(70.3)$ & \\
\hline Anosmia & & & $\mathrm{FE}(0.77)$ \\
\hline Yes & $8(4.1)$ & $4(3.1)$ & \\
\hline No & $189(95.9)$ & $124(96.9)$ & \\
\hline Ageusia & & & $\mathrm{FE}(1)$ \\
\hline Yes & $4(2)$ & $3(2.3)$ & \\
\hline No & $193(98)$ & $125(97.7)$ & \\
\hline $\begin{array}{l}\text { How much did you feel about getting COVID-19 in this hospital } \\
\text { during the first months of COVID-19 epidemic? }\end{array}$ & & & $18.2(<0.001)$ \\
\hline High to very high & $120(42.6)$ & $51(24.1)$ & \\
\hline None to moderate & $162(57.4)$ & $161(75.9)$ & \\
\hline $\begin{array}{l}\text { How much did you feel about getting COVID-19 in this hospital } \\
\text { during this period of COVID-19 epidemic? }\end{array}$ & & & $2.3(0.123)$ \\
\hline High to very high & $130(46.1)$ & $83(39.2)$ & \\
\hline None to moderate & $152(53.9)$ & $129(60.8)$ & \\
\hline $\begin{array}{l}\text { How has been changed your anxiety about getting COVID-19 } \\
\text { from the beginning of its epidemic till now? }\end{array}$ & & & $0.5(0.462)$ \\
\hline Remained high or became high & $121(42.9)$ & $98(46.2)$ & \\
\hline Remained low or became low & $161(57.1)$ & $114(53.8)$ & \\
\hline $\begin{array}{l}\text { How has changed your family's anxiety about your getting } \\
\text { COVID-19 from the beginning of this epidemic till now? }\end{array}$ & & & $4.9(0.026)$ \\
\hline Remained high or became high & $206(73)$ & $135(63.7)$ & \\
\hline Remained low or became low & $76(27)$ & $77(36.3)$ & \\
\hline
\end{tabular}


How much do you know COVID-19 as a virulent disease?

High to very high

None to moderate

Anti-COVID-19 IgG

Positive

Negative

PCR test for COVID-19

Positive

Negative

CT scan of lungs for COVID-19

Positive

Negative

${ }^{a}$ Values are expressed as No. (\%) or mean \pm SD.

${ }^{b}$ Highly Critical, emergency, triage, ICU, isolation room, operation room, recovery room. Semi-critical, admission wards, reception, out-patient clinics, laboratory, pharmacy-radiology, EKG unit, rehabilitation department. Low critical, management, security, transport section, laundry, kitchen, cold room, engineering, research centers, repository.
$0.4(0.499)$

$\begin{array}{ll}131(46.5) & 92(43.4) \\ 151(53.5) & 120(56.6)\end{array}$

$0.3(0.576)$

$$
18(6.4)
$$

$11(5.2)$

$201(94.8)$

$0.03(0.856)$

$28(12.3) \quad 14(11.7)$

$199(87.7)$

$106(88.3)$

FE (0.501)

$17(19.3) \quad 4(26.7)$

$71(80.7) \quad 11(73.3)$
$4(26.7)$ 
Table 2. Univariable Analysis of Associated Factors with Immunity Against COVID-19 in Public Hospital Staff in Shiraz, Iran ${ }^{a}$

\begin{tabular}{|c|c|c|c|c|}
\hline Characteristics & Having Anti-COVID-19 IgG $(N=29)$ & $\begin{array}{l}\text { Not Having Anti-COVID-19 IgG }(\mathrm{N}= \\
446)\end{array}$ & Statistic (P Value) & OR $(\% 95 \mathrm{CI})$ \\
\hline Type of hospital COVID-19 & & & $0.3(0.576)$ & $1.2(0.576-2.7)$ \\
\hline Referral hospital & $18(6.4)$ & $264(93.6)$ & & \\
\hline General hospital & $11(5.2)$ & $201(94.8)$ & & \\
\hline Age, $y$ & $40.4 \pm 10.6$ & $37.2 \pm 8.6$ & $-1.8(0.058)$ & - \\
\hline Gender & & & $0.01(0.919)$ & $0.9(0.4-2)$ \\
\hline Male & $11(6)$ & $172(94)$ & & \\
\hline Female & $18(5.8)$ & $293(94.2)$ & & \\
\hline Marital status & & & $0.2(0.622)$ & $1.2(0.5-2.9)$ \\
\hline Married & $22(6.2)$ & $333(93.8)$ & & \\
\hline Education, y & & & $0.3(0.529)$ & $0.7(0.3-1.8)$ \\
\hline$\hat{a} \%$ a 12 & $7(7.2)$ & $90(92.8)$ & & \\
\hline$>12$ & $22(5.5)$ & $375(94.5)$ & & \\
\hline Field of education & & & $0.006(0.937)$ & $0.9(0.4-2.1)$ \\
\hline Medicine & $11(6)$ & $173(94)$ & & \\
\hline Nursing/others & $18(5.8)$ & $292(94.2)$ & & \\
\hline $\begin{array}{l}\text { Working Department in the } \\
\text { hospital }^{\text {b }}\end{array}$ & & & $2.8(0.089)$ & $0.4(0.2-1.1)$ \\
\hline Highly critical & $22(7.3)$ & $279(92.7)$ & & \\
\hline Semi-critical/low-critical & $7(3.6)$ & $186(96.4)$ & & \\
\hline Type of employment & & & $0.3(0.581)$ & $1.2(0.5-2.8)$ \\
\hline Official & $9(5)$ & $171(95)$ & & \\
\hline Non-official & $19(6.2)$ & $287(93.8)$ & & \\
\hline Work shifts, N/week & $7.5 \pm 1.6$ & $6.9 \pm 2.6$ & $-0.8(0.408)$ & - \\
\hline Type of work shift & & & $7.1(0.007)$ & $4.5(1.3-15.4)$ \\
\hline Rotational & $25(7.9)$ & $293(92.1)$ & & \\
\hline Fixed & $3(1.8)$ & $161(98.2)$ & & \\
\hline Having a chronic disease & & & $1(0.316)$ & $0.613(0.234-1.6)$ \\
\hline Yes & $6(4.5)$ & $126(95.5)$ & & \\
\hline No & $16(7.2)$ & $206(92.8)$ & & \\
\hline $\begin{array}{l}\text { Working in this hospital from the } \\
\text { beginning of COVID-19 epidemic }\end{array}$ & & & $\mathrm{FE}=0.447$ & $0.56(0.165-1.899)$ \\
\hline Yes & $25(6.2)$ & $378(93.8)$ & & \\
\hline No & $3(3.6)$ & $81(96.4)$ & & \\
\hline $\begin{array}{l}\text { Having close contact with a } \\
\text { defined COVID-19 patient(s) within } \\
\text { six months ago }\end{array}$ & & & $0.0(0.986)$ & $1(0.387-2.631)$ \\
\hline Yes & $12(5.4)$ & $209(94.6)$ & & \\
\hline No & $7(5.4)$ & $123(94.6)$ & & \\
\hline
\end{tabular}


Having a history of traveling within six months ago

$\begin{array}{llr}\text { Yes } & 6(4.9) & 117(95.1) \\ \text { No } & 21(6.1) & 326(93.9)\end{array}$

Hosting of traveler(s) within six months ago

\begin{tabular}{|c|}
\hline Yes \\
No \\
Having COVID-19 symptoms within \\
six months ago \\
Yes \\
\hline No
\end{tabular}

$8(4.9)$

$5(6.3)$

$23(5.9)$

20 (6.3)

Result of PCR test for COVID-19

Positive

Negative

$8(4.9)$

154 (95.1)

74 (93.7)

$369(94.1)$

$0.3(0.561)$

$0.779(0.336-1.8)$

$9(21.4) \quad 33(78.6)$

Negative
CT scan of lungs for COVID-19

CT scan of lungs for COVID-19

$13(4.3)$

292 (95.7)

$\begin{array}{lll}\text { Positive } & 7(33.3) & 14(66.7) \\ \text { Negative } & 4(4.9) & 78(95.1)\end{array}$

How much did you feel about

getting COVID-19 in this hospital

during the first months of

COVID-19 epidemic?

\begin{tabular}{|c|c|c|c|c|}
\hline High to very high & $14(8.2)$ & $157(91.8)$ & & \\
\hline None to moderate & $15(4.6)$ & $308(95.4)$ & & \\
\hline $\begin{array}{l}\text { How much did you feel about } \\
\text { getting COVID-19 in this hospital } \\
\text { during this period of COVID-19 } \\
\text { epidemic? }\end{array}$ & & & $0.3(0.563)$ & $0.8(0.38-1.7)$ \\
\hline High to very high & $14(6.6)$ & $199(93.4)$ & & \\
\hline None to moderate & $15(5.3)$ & $266(94.7)$ & & \\
\hline $\begin{array}{l}\text { How has been changed your } \\
\text { anxiety about getting COVID-19 } \\
\text { from the beginning of this } \\
\text { epidemic till now? }\end{array}$ & & & $0.1(0.659)$ & $1.1(0.559-2.5)$ \\
\hline $\begin{array}{l}\text { Remained high or became } \\
\text { high }\end{array}$ & $14(6.4)$ & $205(93.6)$ & & \\
\hline Remained low or became low & $15(5.5)$ & $260(94.5)$ & & \\
\hline $\begin{array}{l}\text { How has changed your family's } \\
\text { anxiety about your getting } \\
\text { COVID-19 from the beginning of } \\
\text { this epidemic till now? }\end{array}$ & & & $0.6(0.403)$ & $0.7(0.331-1.56)$ \\
\hline $\begin{array}{l}\text { Remained high or became } \\
\text { high }\end{array}$ & $18(5.3)$ & $323(94.7)$ & & \\
\hline Remained low or became low & $11(7.2)$ & $142(92.8)$ & & \\
\hline $\begin{array}{l}\text { How much do you know COVID-19 } \\
\text { as a fatal disease? }\end{array}$ & & & $0.1(0.727)$ & $0.8(0.413-1.853)$ \\
\hline High to very high & $14(6.3)$ & $209(93.7)$ & & \\
\hline None to moderate & $15(5.5)$ & $256(94.5)$ & & \\
\hline
\end{tabular}

Observance of standard

precautions 


\begin{tabular}{|c|c|c|c|c|}
\hline $\begin{array}{l}\text { Proper hand washing with soaps } \\
\text { or disinfecting them before and } \\
\text { after contact with any patient or } \\
\text { patients' specimen }\end{array}$ & & & $\mathrm{FE}=1$ & $0.94(0.91-0.96)$ \\
\hline Often to always & $19(5.8)$ & $307(94.2)$ & & \\
\hline None to sometimes & $0(0)$ & $4(100)$ & & \\
\hline $\begin{array}{l}\text { Proper hand washing before and } \\
\text { after removing gloves }\end{array}$ & & & $\mathrm{FE}=1$ & $1(0.136-8.6)$ \\
\hline Often to always & $18(5.8)$ & $293(94.2)$ & & \\
\hline None to sometimes & $1(6.3)$ & $15(93.8)$ & & \\
\hline $\begin{array}{l}\text { Wearing gloves when contacting } \\
\text { patients or their specimens }\end{array}$ & & & $\mathrm{FE}=0.643$ & $1.5(0.325-6.941)$ \\
\hline Often to always & $17(6)$ & $268(94)$ & & \\
\hline None to sometimes & $2(8.7)$ & $21(91.3)$ & & \\
\hline $\begin{array}{l}\text { Proper disposal of used protective } \\
\text { equipment or infectious wastes }\end{array}$ & & & $\mathrm{FE}=0.006$ & $13.7(2.8-66.8)$ \\
\hline Often to always & $16(5.2)$ & $294(94.8)$ & & \\
\hline None to sometimes & $3(42.9)$ & $4(57.1)$ & & \\
\hline $\begin{array}{l}\text { Disinfection of surfaces and } \\
\text { equipment that are in close with } \\
\text { patients }\end{array}$ & & & $\mathrm{FE}=0.251$ & $2.3(0.496-11.3)$ \\
\hline Often to always & $18(6.1)$ & $277(93.9)$ & & \\
\hline None to sometimes & $2(13.3)$ & $13(86.7)$ & & \\
\hline \multicolumn{5}{|l|}{ Observance of droplet precaution } \\
\hline $\begin{array}{l}\text { Keeping a distance of at least } \\
1.5 \text { meters from a patient } \\
\text { suspected of having COVID-19 }\end{array}$ & & & $\mathrm{FE}=0.481$ & $1.4(0.398-5.11)$ \\
\hline Often to always & $18(6.2)$ & $274(93.8)$ & & \\
\hline None to sometimes & $3(8.6)$ & $32(91.4)$ & & \\
\hline $\begin{array}{l}\text { Wearing a medical or surgical } \\
\text { mask when being less than } 1.5 \\
\text { meters away from a patient } \\
\text { suspected of having COVID-19 }\end{array}$ & & & $\mathrm{FE}=1$ & $0.936(0.91-0.964)$ \\
\hline Often to always & $20(6.4)$ & $294(93.6)$ & & \\
\hline None to sometimes & $0(0)$ & $6(100)$ & & \\
\hline $\begin{array}{l}\text { Using goggles or face shields } \\
\text { in the case of close contact } \\
\text { with a patient suspected of } \\
\text { having COVID-19 }\end{array}$ & & & $0.4(0.49)$ & $0.676(0.221-2)$ \\
\hline Often to always & $18(7.8)$ & $213(92.2)$ & & \\
\hline None to sometimes & $4(5.4)$ & $70(94.6)$ & & \\
\hline $\begin{array}{l}\text { Using surgical gowns in the } \\
\text { case of close contact with a } \\
\text { patient suspected of having } \\
\text { COVID-19 }\end{array}$ & & & $\mathrm{FE}=0.219$ & $0.225(0.029-1.726)$ \\
\hline Often to always & $18(7.7)$ & $215(92.3)$ & & \\
\hline None to sometimes & $1(1.9)$ & $53(98.1)$ & & \\
\hline \multicolumn{5}{|l|}{$\begin{array}{l}\text { Observance of airborne } \\
\text { precautions }\end{array}$} \\
\hline $\begin{array}{l}\text { Exclusive use of filtered masks } \\
\text { such as N95 and FFP2 if the } \\
\text { patient's respiratory particles } \\
\text { are suspected to be } \\
\text { aerosolized }\end{array}$ & & & $\mathrm{FE}=0.385$ & $0.455(0.102-2)$ \\
\hline
\end{tabular}




\begin{tabular}{|lcc}
\hline Often to always & $18(7.9)$ & $209(92.1)$ \\
\hline None to sometimes & $2(3.8)$ & $51(96.2)$ \\
$\begin{array}{l}\text { Have you ever passed training } \\
\text { courses about } \\
\text { COVID-19-related isolation } \\
\text { precautions? }\end{array}$ & & FE $=1$ \\
\hline Yes & $19(5.3)$ & $338(94.7)$ \\
\hline No & $3(4.9)$ & $58(95.1)$ \\
\hline
\end{tabular}

Abbreviation: PCR, polymerase chain reaction.

${ }^{a}$ Values are expressed as No. (\%) or mean \pm SD.

${ }^{\mathrm{b}}$ Highly critical, emergency, triage, ICU, isolation room, operation room, recovery room. Semi-critical, admission wards, reception, out-patients clinics, laboratory,

pharmacy-radiology, EKG unit, rehabilitation department. Low critical, management, security, transport section, laundry, kitchen, cold room, engineering, research centers, repository. 